\title{
Physicochemical Characterization of Porous Materials: Spatially Resolved Accessibility of Zeolite Crystals**
}

\author{
Sander van Donk, Johannes H. Bitter,* \\ An Verberckmoes, Marjan Versluijs-Helder, \\ Alfred Broersma, and Krijn P. de Jong
}

Zeolites and (ordered) mesoporous materials are essential building blocks of functional materials used in, for example, adsorption, separation, and catalysis. ${ }^{[1]}$ Key factors governing the performance of these materials are pore size, pore shape, surface properties, and the like. In many applications, especially for zeolites, the molecules involved either as substrate or product have similar sizes to those of the pores. $^{[2]}$ This leads to molecular-sieving properties relevant for adsorption and separation processes and shape selectivity in catalysis. Likewise, the rate of access of molecules into zeolite crystals may be low or sometimes even zero if pore blocking by impurities occurs. To improve the accessibility of zeolites many different approaches have been followed, such as the synthesis of zeolites with large pores, ${ }^{[3-7]}$ small crystals, ${ }^{[8]}$ hierarchical structures,${ }^{[9]}$ and mesoporous crystals. ${ }^{[1,10,11]}$ In all cases, however, one clearly needs reliable methods for the characterization of the accessibility of these materials. Adsorption studies, ${ }^{[12]}$ often in combination with spectroscopy ${ }^{[13-16]}$ have been used until now to establish the average accessibility of the micropore volume of zeolite samples. Progress has been made in recent years in obtaining information on the accessibility of porous materials with techniques such as magnetic resonance imaging (MRI $)^{[17]}$ or interference microscopy ${ }^{[18]}$ with a spatial resolution of millimeters and micrometers, respectively. Herein, we use adsorption and diffusion studies in combination with scanning electron microscopy/energy-dispersive X-ray (SEM/EDX) analysis, which allow us to determine quantitatively the

[*] Dr. J. H. Bitter, M. Versluijs-Helder, A. Broersma, Prof. K. P. de Jong Department of Inorganic Chemistry and Catalysis

Debye Institute, Utrecht University

P.O. Box 80083,3508 TB Utrecht (The Netherlands)

Fax: (+31) 30-251-1027

E-mail: j.h.bitter@chem.uu.nl

Dr. S. van Donk ${ }^{[+]}$

Utrecht University

P.O. Box 80083, 3508 TB Utrecht (The Netherlands)

Dr. A. Verberckmoes

ExxonMobil Chemical Europe Inc.

European Technology Center, Machelen (Belgium)

$\left[{ }^{+}\right]$Current address: Albemarle Catalysts

Research Center Amsterdam (The Netherlands)

[**: Katleen Hermans (ExxonMobil) is acknowledged for performing the ICP-AES and ${ }^{27} \mathrm{Al}$ NMR measurements; Jeroen van Bokhoven (ETH Zürich) and Andrea Battiston (UU/Albemarle Catalysts) are acknowledged for helpful discussions. This work was financially supported by the Netherlands Organization for Scientific Research (NWO/CW 700-97-019). 
length of the accessible micropores of zeolite crystals with a resolution of $50 \mathrm{~nm}$ or better. As a case in point, we will study the accessibility of the zeolite mordenite (MOR).

Mordenite is of great industrial importance in the catalytic conversion of alkanes ${ }^{[19,20]}$ and aromatic compounds. ${ }^{[21]}$ The structure of MOR is generally regarded as one-dimensional, ${ }^{[22,23]}$ with the 12-ring (12-MR) channels running parallel to the length of the crystal. ${ }^{[2]}$ Several times in the past it has been qualitatively observed that the presence of either small amounts of nonframework alumina (NFAl) or crystal-growth defects caused blockage of a large part of the micropore volume. ${ }^{[12,25,26]}$ This blockage makes it impossible for hydrocarbons to enter the micropores and consequently the catalytic action is largely hindered, which makes this system an ideal case to demonstrate the value of the new combination of techniques.

Sodium-exchanged zeolite (NaMOR) with a Si/Al ratio of $5.5: 1$ was synthesized by using a modified literature procedure. ${ }^{[27]}$ The $\mathrm{Na}^{+}$ions were exchanged for $\mathrm{NH}_{4}{ }^{+}$ions to give $\mathrm{NH}_{4} \mathrm{MOR}$, which was subsequently calcined in air at $723 \mathrm{~K}$ for $6 \mathrm{~h}\left(\mathrm{ramp} 1 \mathrm{Kmin}^{-1}\right)$ to obtain HMOR. From the literature it is known that NFAl species that are created during synthesis or calcination can be removed by a mild treatment using oxalic acid. ${ }^{[28,29]}$ Therefore, part of the HMOR sample was treated in an aqueous solution of $0.1 \mathrm{M}$ oxalic acid at $353 \mathrm{~K}$ for $1 \mathrm{~h}$. The sample was then filtered, washed, dried at $353 \mathrm{~K}$ for $12 \mathrm{~h}$, and calcined as described before. This treatment was executed twice to give a sample that is referred to as HMOR-ox. Both the HMOR and HMOR-ox samples were characterized by using nitrogen physisorption/t-plot analysis, elemental analysis by inductively coupled plasma atomic-emission spectrometry (ICPAES), temperature-programmed desorption-thermogravimetric analysis (TPD-TGA) with $n$-propylamine, ${ }^{27} \mathrm{Al} \mathrm{NMR}$ spectroscopy, and SEM.

The physicochemical characteristics of HMOR and HMOR-ox are presented in Table 1. Elemental analysis shows that the mild treatment with oxalic acid causes an increase in the $\mathrm{Si} / \mathrm{Al}$ ratio from 5.6:1 to 8.0:1 (at/at). Despite the removal of aluminum by oxalic acid, the SEM images for both samples were indistinguishable, with average crystal lengths $(2 L)$ of between 1 and $2 \mu \mathrm{m}$. Evaluation by ${ }^{27} \mathrm{Al} \mathrm{NMR}$ spectroscopy also indicated that upon treatment with oxalic acid, the overall amount of $\mathrm{Al}$ in the sample decreased. In particular, the peak at $0 \mathrm{ppm}$ that is generally ascribed to octahedral NFAl species ${ }^{[30,31]}$ was lowered, which indicates

Table 1: Characterization data of the HMOR samples.

\begin{tabular}{lll}
\hline & HMOR & HMOR-ox \\
\hline bulk Si/Al ratio, ICP-AES (at/at) & 5.6 & 8.0 \\
$2 L$ from SEM $[\mu \mathrm{m}]$ & $1-2$ & $1-2$ \\
micropore volume $\left[\mathrm{mL} \mathrm{g}^{-1}\right]$ & 0.16 & 0.17 \\
external surface area $\left[\mathrm{m}^{2} \mathrm{~g}^{-1}\right]$ & 67 & 52 \\
acid sites, TPD-TGA $\left[\mathrm{mmol} \mathrm{g}^{-1}\right]$ & 0.29 & 0.73 \\
$n$-hexane uptake at $523 \mathrm{~K}[\mathrm{wt} \%]$ & 0.56 & 1.53 \\
$L^{2} / D$ from $n$-hexane uptake $[\mathrm{s}]$ & 85 & 797 \\
$L_{\text {calcd }}$ from $n$-hexane uptake $[\mu \mathrm{m}]$ & 0.16 & 0.49 \\
$n$-butene-derived coke at $623 \mathrm{~K}[\mathrm{wt} \%]$ & 3.7 & 8.2 \\
$L_{\text {coke }}$ from SEM-EDX $[\mu \mathrm{m}]$ & $\approx 0.2$ & $\approx 1$ \\
\hline
\end{tabular}

that NFAl had been removed. A minor amount of tetrahedral species was also removed; however, from the measured data it was not clear if this concerned framework $\mathrm{Al}$ or NFAl species. The nitrogen physisorption results presented in Table 1 suggest that no significant changes in the textural properties occurred during the oxalic acid treatment. However, the number of acid sites probed by $n$-propylamine increased by almost a factor of 3 upon leaching, while the level of aluminum was significantly lower.

Different techniques are available for studying the diffusion behavior in zeolites, such as IR spectroscopy, ${ }^{[32]}$ zero-length column (ZLC) chromatography, ${ }^{[33]}$ and pulsed field gradient (PFG) NMR spectroscopy. ${ }^{[34]}$ We chose to further investigate this discrepancy by performing transient uptake measurements for $n$-hexane in a tapered-element oscillating microbalance (TEOM; Rupprecht \& Pataschnick 1500 PMA). ${ }^{[35-37]}$ The measurements were carried out at $523 \mathrm{~K}$ and a total pressure of 1.3 bar. The results for the uptake of $n$-hexane are shown in Figure 1, which reveals a

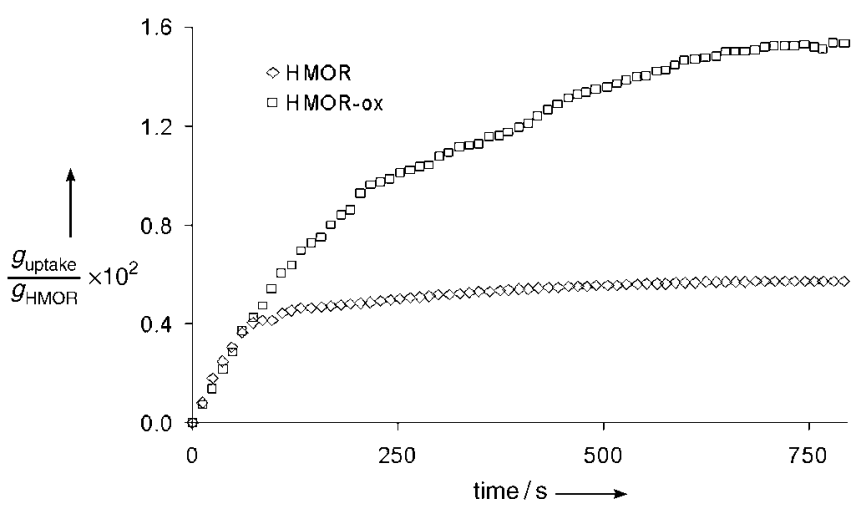

Figure 1. Experimental uptake curves for $n$-hexane over HMOR and HMOR-ox at $523 \mathrm{~K}$, as monitored by a TEOM.

significant difference in the equilibrium uptake of $n$-hexane by HMOR and HMOR-ox. The amount of $n$-hexane adsorbed in the micropores almost tripled from $0.56 \mathrm{wt} \%$ for HMOR to $1.53 \mathrm{wt} \%$ for HMOR-ox (see also Table 1), which indicates a higher availability of micropore volume for HMOR-ox. Quantitative information on the nature of pore blocking could be deduced from the uptake data. The characteristic times for diffusion $L^{2} / D[\mathrm{~s}]$, where $D\left[\mathrm{~m}^{2} \mathrm{~s}^{-1}\right]$ is the diffusion coefficient, were derived by fitting the experimental uptake curves for HMOR and HMOR-ox using a model described in an earlier study. ${ }^{[35]}$ The data presented in Table 1 clearly indicate that the acid treatment induces an almost tenfold increase in $L^{2} / D$. The accessible pore lengths for the two samples were calculated $\left(L_{\text {calcd }}\right.$ in Table 1) using a literature value $\mathrm{e}^{[35]}$ for $D$ of $3 \times 10^{-16} \mathrm{~m}^{2} \mathrm{~s}^{-1}$. The resulting value of $0.16 \mu \mathrm{m}$ for HMOR is much lower than one would expect from the SEM measurements. However, for HMOR-ox, the value of $L_{\text {calcd }}$ is close to that expected.

The accessible pore lengths for HMOR and HMOR-ox were further investigated by exposing the samples to pure $n$ butene for $20 \mathrm{~h}$ at $623 \mathrm{~K}$ and 1.3 bar in the TEOM, to provoke coke formation. The coke contents were $3.7 \mathrm{wt} \%$ for HMOR 
and $8.2 \mathrm{wt} \%$ for HMOR-ox, which reveals a similar trend to that observed with the $n$-hexane uptake measurements (Table 1). The coked HMOR crystals were also investigated in an SEM microscope (Philips XL30FEG) equipped with an EDX detector. Line scans were taken over the HMOR samples such that the atomic carbon (C) and zeolitic oxygen (O) signals were monitored parallel to the direction of the 12$\mathrm{MR}$ channels. The $\mathrm{C} / \mathrm{O}$ ratio was calculated from these data to determine the penetration depth of the carbonaceous deposits into the 12-MR channels. Figure 2 shows representative

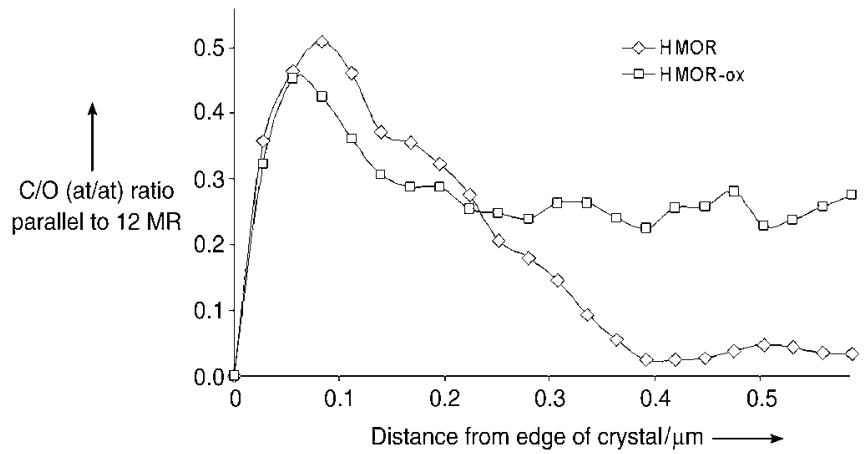

Figure 2. Coke profiles for HMOR and HMOR-ox, which show the atomic carbon to zeolitic oxygen $(\mathrm{C} / \mathrm{O})$ ratio as a function of scanning distance going from the edge to the inside of the crystal, as monitored by SEM-EDX.

line scans for HMOR and HMOR-ox crystals. The observed $\mathrm{C} / \mathrm{O}$ ratios provide us with an estimate of the accessible pore length. For HMOR-ox the butene molecules have reacted throughout the pores, while for HMOR similar uptake occurs only up to $0.2 \mu \mathrm{m}$ and total blockage is apparent beyond $0.4 \mu \mathrm{m}$. These data allow direct visualization of the accessible pore lengths for the two samples by their coke profiles $\left(L_{\text {coke }}\right.$ in Table 1), and clearly indicate the enhanced length of the accessible micropores for HMOR-ox in comparison with HMOR (Figure 3). In addition, the value of $0.2 \mu \mathrm{m}$ for the accessible pore length of HMOR obtained from EDX agrees very well with the value of $0.16 \mu \mathrm{m}$ calculated from the $n$ hexane uptake measurements. In general, the gradient of coke observed over the HMOR-ox crystal points to masstransfer limitation of the deposition process, which has been observed before for the reaction of $n$-butene over ferrierite. ${ }^{[38]}$

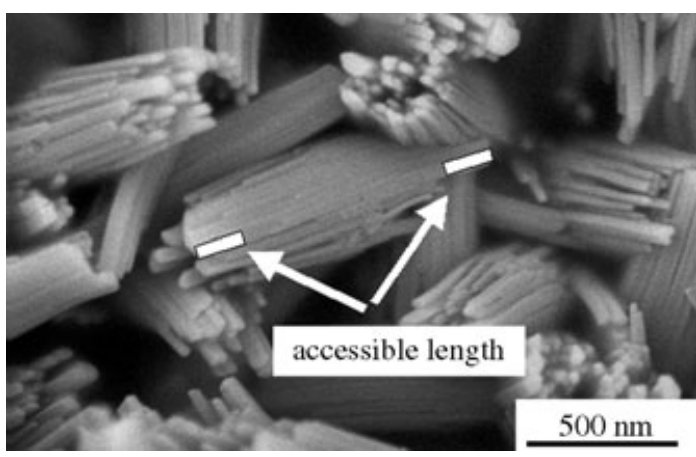

Figure 3. SEM image of HMOR. The accessible pore length is indicated by the white areas. Only $30 \%$ of the pore is accessible.
Careful selection of probe molecules allows the methods of diffusion (TEOM) and coking (SEM/EDX) to be generalized for accessibility studies of a range of microporous and mesoporous materials. If a higher spatial resolution is needed than that obtained with SEM/EDX, one can use scanning TEM/electron energy-loss spectroscopy (STEM/EELS) to detect coke profiles with about $2-\mathrm{nm}$ resolution. ${ }^{[38]}$

Received: June 15, 2004

Revised: November 23, 2004

Published online: January 20, 2005

Keywords: diffusion - mesoporous materials . microporous materials · physisorption · zeolites

[1] A. Corma, J. Catal. 2003, 216, 298.

[2] S. van Donk, A. H. Janssen, J. H. Bitter, K. P. de Jong, Catal. Rev. 2003, 45, 297.

[3] A. Corma, M. J. Diaz-Cabanas, J. Martinez-Triguero, F. Rey, J. Ruis, Nature 2002, 418, 514.

[4] J.-L. Pailloud, B. Harbuzaru, J. Patarin, N. Bats, Science 2004, 304, 990.

[5] A. Corma, U. Diaz, M. E. Domine, V. Fornes, Angew. Chem. 2000, 112, 1559; Angew. Chem. Int. Ed. 2000, 39, 1499.

[6] C. T. Kresge, M. E. Leonowicz, W. J. Roth, J. C. Vartuli, J. S. Beck, Nature 1992, 359, 710.

[7] A. Corma, M. J. Diaz-Cabanas, F. Rey, S. Nicolopoulus, K. Boulahya, Chem. Commun. 2004, 1356.

[8] G. Belussi, G. Pazzuconi, C. Perego, G. Girotti, G. Terzoni, J. Catal. 1995, 157, 227.

[9] S. S. Kim, A. Karkamkar, T. J. Pinnavaia, M. Kruk, J. Phys. Chem. B 2001, 105, 7663.

[10] A. H. Janssen, A. J. Koster, K. P. de Jong, Angew. Chem. 2001, 113, 1136; Angew. Chem. Int. Ed. 2001, 40, 1102.

[11] C. J. H. Jacobson, C. Madsen, J. Houzvicka, I. Schmidt, A. Carlsson, J. Am. Chem. Soc. 2000, 122, 7116.

[12] Y. Hong, J. J. Fripiat, Microporous Mater. 1995, 4, 323.

[13] G. Muller, T. Narbeshuber, G. Mirth, J. A. Lercher, J. Phys. Chem. 1994, 98, 7436.

[14] T. Armaroli, M. Bevilacqua, M. Trombetta, F. Milella, A. G. Alejandre, J. Ramirez, B. Notari, R. J. Willey, G. Busca, Appl. Catal. A 2001, 216, 59.

[15] I. I. Ivanova, V. Montouillout, C. Fernandez, O. Marie, J-P. Gilson, Microporous Mesoporous Mater. 2003, 57, 297.

[16] N. A. Nesterenko, F. Thibault-Starzyk, V. Montouillout, V. V. Yuschenko, C. Fernandez, J.-P Gilson, F. Fajula, I. I. Ivanova, Microporous Mesoporous Mater. 2004, 71, 157.

[17] S. P. Rigby, L. F. Gladden, J. Catal. 1998, 173, 484

[18] P. Kortunov, S. Vasenkov, C. Chmelik, J. Kärger, D. M. Ruthven, J. Wloch, Chem. Mater. 2004, 16, 3552

[19] H. W. Kouwenhoven, W. C. van Zijl-Langhout, Chem. Eng. Prog. 1971, 67, 65.

[20] A. Corma, A. Martinez, Catalytic Activation and Functionalization of Light Alkanes: Advances and Challenges (Eds.: E. G. Derouane, J. Haber, F. Lemos, F. R. Ribeiro, M. Guisnet), Kluwer Academic, Dordrecht, 1998.

[21] G. J. Lee, J. M. Garces, G. R. Meima, M. J. M. van der Aalst, US Patent no. 325177, 1989.

[22] A. W. O’Donovan, C. T. O’Connor, K. R. Koch, Microporous Mater. 1995, 5, 185.

[23] F. Eder, M. Stockenhuber, J. A. Lercher, J. Phys. Chem. B 1997, $101,5414$.

[24] C. Baerlocher, W. M. Meier, D. H. Olson, Atlas of Zeolite Framework Types, 5th ed., Elsevier Science, Amsterdam, 2001. 
[25] L. D. Fernandez, P. E. Bartl, J. L. F. Monteiro, J. G. Dasilva, S. C. Demendez, M. J. B. Cardoso, Zeolites 1994, 14, 533.

[26] S. Moreno, G. Poncelet, Microporous Mater. 1997, 12, 197.

[27] P. K. Bajpai, Zeolites 1986, 6, 2.

[28] M. R. Apelian, A. S. Fung, G. J. Kennedy, T. F. Degnan, J. Phys. Chem. 1996, 100, 16577.

[29] M. Müller, G. Harvey, R. Prins, Microporous Mesoporous Mater. 2000, 34, 135.

[30] R. Giudici, H. W. Kouwenhoven, R. Prins, Appl. Catal. A 2000 $203,101$.

[31] T.-H. Chen, B. H. Wouters, P. J. Grobet, Eur. J. Inorg. Chem. 2000, 2,281 .

[32] H. G. Karge, W. Niessen, Catal. Today 1991, 8, 451.

[33] M. Eic, D. M. Ruthven, Zeolites 1988, 9, 40.

[34] R. Valiullin, P. Kortunov, J. Kärger, V. Timoshenko, J. Chem. Phys. 2004, 120, 11804.

[35] S. van Donk, A. Broersma, O. L. J. Gijzeman, J. A. van Bokhoven, J. H. Bitter, K. P. de Jong, J. Catal. 2001, 204, 272.

[36] D. Chen, H. P. Rebo, K. Moljord, A. Holmen, Chem. Eng. Sci. 1996, $51,2687$.

[37] W. Zhu, J. M. van de Graaf, L. J. P. van den Broeke, F. Kapteijn, J. A. Moulijn, Ind. Eng. Chem. Res. 1998, 37, 1934.

[38] S. van Donk, F. M. F. de Groot, O. Stéphan, J. H. Bitter, K. P. de Jong, Chem. Eur. J. 2003, 9, 3106. 